\title{
Access to mass media messages, and use of family planning in Nigeria: a spatio- demographic analysis from the 2013 DHS
}

\author{
Chukwuedozie K. Ajaero ${ }^{1,2^{*}}$, Clifford Odimegwu², ljeoma D. Ajaero ${ }^{3}$ and Chidiebere A. Nwachukwu ${ }^{3}$
}

\begin{abstract}
Background: Nigeria has the highest population in sub-Saharan Africa with high birth and growth rates. There is therefore need for family planning to regulate and stabilize this population. This study examined the relationship between access to mass media messages on family planning and use of family planning in Nigeria. It also investigated the impacts of spatio-demographic variables on the relationship between access to mass media messages and use of family planning.
\end{abstract}

Methods: Data from the 2013 demographic and health survey of Nigeria which was conducted in all the 36 states of Nigeria, and Abuja were used for the study. The sample was weighted to ensure representativeness. Univariate, bivariate and binary logistic regressions were conducted. The relationship between each of the access to mass media messages, and the family planning variables were determined with Pearson correlation analysis.

Results: The correlation results showed significant but weak direct relationships between the access to mass media messages and use of family planning at $p<0.0001$ with access to television messages $(r=0.239)$ being associated with highest use of family planning. Some of the results of the adjusted regression analysis showed that access to television messages $(O R=1.2 .225 ; p<0.0001)$, and radio messages $(O R=1.945 ; p<0.0001)$ increase the likelihood of the use of family planning. The adjusted regression model also indicated increased likelihood in the use of family planning by respondents with secondary education $(\mathrm{OR}=2.709 ; p<0.0001)$, the married $(\mathrm{OR}=1.274 ; p<0.001)$, and respondents within the highest wealth quintiles $(\mathrm{OR}=3.442 ; p<0.0001)$.

Conclusions: There exist significant variations within spatio-demographic groups with regards to having access to mass media messages on family planning, and on the use of family planning. The results showed that access to mass media messages increases the likelihood of the use of family planning. Also people with higher socioeconomic status and those from the Southern part of the country make more use of family planning. There is need to improve the socioeconomic status of the populations. Also, the quality and regularity of mass media messages should be improved, while other communication avenues such as traditional institutions, blogs, and seminars for youths should be used to make family planning messages more acceptable.

Keywords: Family planning, Mass media messages, Nigeria, Spatio-demographic, characteristics

\footnotetext{
* Correspondence: chukwuedozie.ajaero@unn.edu.ng

'Department of Geography, University of Nigeria Nsukka, Nsukka, Nigeria

${ }^{2}$ Demography and Population Studies Programme, University of the

Witwatersrand, Johannesburg, South Africa

Full list of author information is available at the end of the article
} 


\section{Background}

Many countries, especially in sub-Saharan Africa face population related problems like spiraling population growth and contracting economy, resulting in situations where nations are unable to muster adequate socioeconomic resources to cater to the needs of their citizens [1]. Added to this is the need to promote reproductive health which can be harmed by uncontrolled child bearing, and unprotected sex, leading to avoidable social dislocations. It is in the realization of the importance of keeping tabs on population growth and reproductive health that nations, international agencies and non-governmental organizations (NGOs) spend time and resources to promote family planning.

One of the strategies often employed in the promotion of family planning is the utilization of the mass media to make populations aware of the benefits of the use of family planning. The reason for this is located in the fact that information can have a positive influence on people's attitude and actions. Research has also shown that depending on the goals of a family planning intervention, such communications can create awareness, increase knowledge and lead to a desired behavioral change [2-12]. For instance, a study in Akwa Ibom, Nigeria found that of the respondents who had been exposed to favorable information about family planning, 46.9 percent had used family planning in contrast with the respondents who were exposed to unfavorable information about family planning, 87.4 percent of who did not use family planning [13]. Also, lack of knowledge and misconceptions about family planning have been strongly linked with non-use of family planning methods [14].

Furthermore, the mass media as credible sources of information have the capacity to raise awareness, increase knowledge level, and influence attitudes towards family planning $[1,15,16]$. Also, another work [6] in Kenya also found that access to media messages affected ever use of contraceptives, current use, intention to use contraceptives and desire for future births. In addition, several studies have focused on how mass media campaigns on family planning have led to improvement in reproductive health in different countries [10, 17-25]. In addition, it has been noted that social marketing could also be used together with the mass media to promote reproductive health [26].

The is also evidence from literature that use of family planning may result to various adverse effects as an increase in paternal age decreases semen quality and prolongs the time of conception for women [27, 28], increases pregnancy complications [29], and results in adverse health outcomes for children [30]. Conversely, family planning has been associated with several benefits. These include reduction in maternal deaths as number of deaths is reduced, and there is a decrease in the number of unsafe abortions from unintended pregnancies [31] even as family planning helps the women to plan their pregnancies and postpone child bearing [32, 33]. Family planning also contributes to gender equality [34] as these women can acquire tertiary education, and increase their chances of employment and higher incomes [35-38].

However, irrespective of the benefits promoted in family planning interventions, people do not respond alike to them. Family planning campaigns may raise awareness about family planning, its benefits and methods without a corresponding rise in the number of people adopting the promoted measures. This is as a result of some intervening variables such as education, marital status, income, and spousal relationships that influence people's attitude to family planning [39-43]. Furthermore, it has been found that though there was a high level of awareness about family planning in a rural community in Nigeria as a result of a media campaign, the adoption of the new family planning methods remains low [1]. This low uptake of the modern methods was attributed to the desire of the average rural Nigerian household for large family size, and the need to have more male children. This low adoption of modern family planning methods evident in rural Nigeria is also consistent with the findings of other works in Ghana and Nigeria [14, 15]. While educational attainment has a positive relationship with approval of family planning and knowledge of specific methods [14, 15, 44], other predictors of family planning usage in Nigeria include ethnicity, religion, spousal approval and communication with spouse [45].

Consequently, the role of the mass media cannot be ignored in the pursuit of improved maternal and reproductive health in Nigeria. Since studies have shown that the media can influence people positively in adopting family planning methods, it is suggested that "intense campaign exposure, may be necessary to change behavior, but moderate exposure and access to mass media messages may be sufficient to change attitudes and stimulate discussion" [10]. However, a nationally representative empirical study on how mass media messages and spatio-demographic characteristics of the population affect the uptake of family planning in Nigeria is lacking. It is against this backdrop that this study examined the relationship between access to mass media messages on family planning and the use of family planning in Nigeria. It also investigated the impacts of spatiodemographic variables on the relationship between access to mass media messages and family planning, using data from the 2013 demographic and health survey of Nigeria which was conducted in all the 36 states of Nigeria, and Abuja. The findings will be useful in 
identifying ways of improving the effectiveness of the mass media, and spatio-demographic characteristics in improving the use of family planning in Nigeria.

\section{Methods \\ Data collection}

The data for this study is the 2013 Nigeria Demographic and Health Survey (DHS) which is the fourth survey to be implemented by the National Population Commission (NPC) of Nigeria and ICF International USA in association with USAID, UKaid, and UNFPA. The survey was carried out on a nationally representative sample of 38,948 women age $15-49$ in 15,859 urban and 22, 663 rural households from all the 36 States and Federal Capital Territory (FCT) of Nigeria. The response rates for this survey among women aged 15-49 years are $97.3 \%$ in the urban areas and $97.8 \%$ in the rural areas. The sampling frame used for the survey was generated from the results of the 2006 Population and Housing Census of Nigeria- the most recent census of Nigeria. The sampling frame for the 2006 census made use of states, in which the states are subdivided into local government areas (LGAs), each LGA subdivided into localities, and each locality subdivided into enumeration areas (EAs). Consequently, the primary sampling unit (PSU) otherwise referred to as a cluster for the DHS was defined on the basis of EAs adopted in the 2006 census. It should also be noted here that these 36 states in Nigeria have been grouped into six geo-political zones based on geographical spread and environmental conditions. The six zones are North Central, North East, North West, South East, South South, and South West. The sample was subsequently selected using a stratified three-stage cluster design made up of 372 urban clusters and 532 rural clusters, totaling 904 clusters in all. In each cluster, 45 households were selected and all the women aged 15-49 who are either permanent residents or visitors present in the households were eligible to be interviewed. Finally, the spatial representation of the data collected from the survey was therefore on the basis geo-political zones, States, and rural/urban residence.

\section{Variables used for the study}

This study utilized three major categories of variables which are further classified into independent and dependent variables. These three variables are; current use of family planning(dependent/outcome variable); access to mass media messages on family planning (independent dummy variables); and spatio-demographic variables (independent variables).

The current use of family planning (dependent/outcome variable) denotes whether traditional or modern methods are used, so long as any type of planning were used by women age 15-49 years. The justification for this is to ascertain the general level of current use of family planning as using only the modern methods of family planning in the analysis may exclude some people who because of their place of residence, wealth index or religious affiliation may not subscribe to certain modern methods of family planning but may be comfortable with the traditional methods despite having access to messages on modern methods of family planning from the mass media. This variable is measured as a dichotomous variable coded as use of family planning method or nonuse of family planning method.

In terms of the independent variables, access to mass media messages on the family were examined using messages about family planning got from radio, television or newspaper. These media messages were also measured as dichotomous variables coded as having access or not having access to family planning messages. Finally, the categorical spatio-demographic variables are (i) rural/ urban residence (ii) geopolitical zone/region (iii) fiveyear age group (iv) education (v) wealth index (vi) employment status, (vii) religion, and (vii) marital status of respondents.

\section{Data analysis}

Before the commencement of data analysis, the dataset was weighted to account for differences due to undersampling and over sampling as per the survey design using the stata svyset command. Subsequently, the analysis of the data involved univariate analysis of the characteristics of the study population. Also, bivariate analyses of spatio-demographic characteristics and each of the access to mass media messages on family planning variables and the current use of family planning were carried out using Pearson chi-square test. Pearson correlation was used to examine the relationship between each of the access to mass media messages on family planning and the use of family planning services. Finally, binary logistic regressions were used to estimate the access to mass media messages and spatio-demographic predictors of use of family planning in Nigeria. The regression coefficients of the independent variables are expressed as Odds Ratio (OR). A variable with Odds Ratio greater than 1.00 implied that the variable increases the likelihood of the outcome (use of family planning) while it is the opposite when the OR is less than 1.00 . Consequently, three regression models are generated for this study namely models 1,2 and 3 . Model 1 is the unadjusted model of current use family planning and each of the independent variables while, in model 2 represents the adjusted model of current use of family planning and all the three variables of access to messages on family planning from radio, television, and newspapers. Finally, Model 3 is the adjusted model of current use of family planning and all the independent variables of 
access to mass media messages, and the spatiodemographic characteristics.

\section{Ethical considerations}

This study is a secondary analysis of anonymous data from the Nigeria Demographic and Health Survey (DHS) 2013. The survey was approved by the National Health Research Ethics Committee in Nigeria (Approval no: NHREC/01/01/2007). Informed consent was obtained from respondents during the process of data collection. Formal approval to use the data was also obtained from the DHS program.

\section{Results}

\section{Characteristics of the sample population}

A total of 38,948 women aged 15-49 years were interviewed during the Nigeria 2013 Demographic and Health that covered the 36 states and the FCT of Nigeria (Table 1). Generally, the proportion of respondents decreased with increasing age in the number of years while more of the respondents (57.9\%) lived in rural areas as against $42.1 \%$ living in urban areas. These show that the population was relatively a young one even as the majority of the Nigerian populace lived in rural areas. Furthermore, respondents with no education were more in number $(14,729)$ compared to women with secondary education $(13,927)$, and those with more than secondary education $(3,558)$. The respondents across the various wealth index quintiles were relatively equally distributed, but those in the highest wealth index $(8,910)$ constituted the greatest proportion of the population. In terms of spatial distribution, the North West population (30.5\%) had the largest number of respondents while the South East (11.5 \%) constituted the smallest proportion of respondents. Finally, both the never married $(23.9 \%)$ and the married (69.4\%) together made up more than $90 \%$ of respondents sampled in terms of marital status (Table 1).

\section{Bivariate analyses of access to mass media messages, and} the use of family planning

The results of the bivariate and Chi-square analyses revealed that all the socio-demographic characteristics were significantly associated with all the four variables of; current use of family planning; and access to mass media information about family planning from television, from radio, and from newspapers (Table 2). Generally, the results of access to mass media messages show that an increase in socio-economic status of the respondents led to an increase in their probability of getting access to family planning messages from the various mass media. For instance, while $13.45 \%$ of people with no education had access to radio messages, $67.55 \%$ of respondents with postsecondary education got information about family
Table 1 Characteristics of the study population

\begin{tabular}{|c|c|c|}
\hline $\begin{array}{l}\text { Spatio-demographic } \\
\text { characteristics }\end{array}$ & $\begin{array}{l}\text { Weighted } \\
\text { frequency }\end{array}$ & $\begin{array}{l}\text { Weighted } \\
\text { percent }\end{array}$ \\
\hline \multicolumn{3}{|l|}{ Age group } \\
\hline $15-19$ & 7,820 & 20.1 \\
\hline $20-24$ & 6,757 & 17.3 \\
\hline $25-29$ & 7,145 & 18.3 \\
\hline $30-34$ & 5,467 & 14 \\
\hline $35-39$ & 4,718 & 12.1 \\
\hline $40-44$ & 3,620 & 9.3 \\
\hline $45-49$ & 3,422 & 8.8 \\
\hline \multicolumn{3}{|l|}{ Education } \\
\hline No education & 14,729 & 37.8 \\
\hline Primary & 6,734 & 17.3 \\
\hline Secondary & 13,927 & 35.8 \\
\hline Higher & 3,558 & 9.1 \\
\hline \multicolumn{3}{|l|}{ Marital Status } \\
\hline Never married & 9,326 & 23.9 \\
\hline Married & 27,043 & 69.4 \\
\hline Living with Partner & 787 & 2 \\
\hline Divorced/sep & 826 & 2.1 \\
\hline Widowed & 967 & 2.5 \\
\hline \multicolumn{3}{|l|}{ Region } \\
\hline North Central & 5,572 & 14.3 \\
\hline North East & 5,766 & 14.8 \\
\hline North West & 11,877 & 30.5 \\
\hline South East & 4,476 & 11.5 \\
\hline South South & 4,942 & 12.7 \\
\hline South West & 6,314 & 16.2 \\
\hline \multicolumn{3}{|l|}{ Residence } \\
\hline Urban & 16,414 & 42.1 \\
\hline Rural & 22,534 & 57.9 \\
\hline \multicolumn{3}{|l|}{ Wealth Index } \\
\hline Lowest & 7,132 & 18.3 \\
\hline Second & 7,428 & 19.1 \\
\hline Middle & 7,486 & 19.2 \\
\hline Fourth & 7,992 & 20.5 \\
\hline Highest & 8,910 & 22.9 \\
\hline
\end{tabular}

planning from the radio. In terms of the regions of respondents, $14.62 \%$ of people from North East got information from the radio as against $63.66 \%$ from the South West. Also, $8.29 \%$ of people in the lowest wealth quintile had access to radio information compared to $57.84 \%$ from the highest wealth quintile.

Access to family planning information from television varies significantly among the various socio-demographic groups as $10.03 \%$ of rural residents could access family 
Table 2 Bivariate and Chi-Square analyses of access to mass media messages, and use of family planning

\begin{tabular}{|c|c|c|c|c|c|c|c|c|c|c|c|c|}
\hline \multirow{2}{*}{$\begin{array}{l}\text { Spatio-demographic } \\
\text { characteristics }\end{array}$} & \multicolumn{3}{|l|}{ Radio } & \multicolumn{3}{|l|}{ TV } & \multicolumn{3}{|l|}{ N P } & \multicolumn{3}{|l|}{ FP } \\
\hline & yes & $\%$ & sig. & yes & $\%$ & sig. & yes & $\%$ & sig. & yes & $\%$ & sig. \\
\hline \multicolumn{13}{|l|}{ Age group } \\
\hline $15-19$ & 1,911 & 24.20 & 0.000 & 1,088 & 13.79 & 0.000 & 352 & 4.47 & 0.000 & 539 & 6.82 & 0.000 \\
\hline $20-24$ & 2,167 & 32.31 & & 1,324 & 19.74 & & 508 & 7.59 & & 1,192 & 17.75 & \\
\hline $25-29$ & 2,538 & 36.09 & & 1,635 & 23.26 & & 585 & 8.83 & & 1,260 & 17.91 & \\
\hline $30-34$ & 1,992 & 37.12 & & 1,280 & 23.86 & & 466 & 8.70 & & 1,033 & 19.23 & \\
\hline $35-39$ & 1,734 & 36.89 & & 1,060 & 22.58 & & 365 & 7.78 & & 976 & 20.76 & \\
\hline $40-44$ & 1,270 & 34.69 & & 812 & 22.19 & & 286 & 7.82 & & 776 & 21.18 & \\
\hline $45-49$ & 1,146 & 32.25 & & 671 & 18.90 & & 205 & 5.77 & & 449 & 12.63 & \\
\hline \multicolumn{13}{|l|}{ Education } \\
\hline No education & 1,846 & 13.45 & 0.000 & 331 & 2.41 & 0.000 & 32 & 0.23 & 0.000 & 400 & 2.91 & 0.000 \\
\hline Primary & 2,214 & 31.17 & & 1,120 & 15.78 & & 194 & 2.74 & & 1,210 & 17.03 & \\
\hline Secondary & 6,204 & 43.10 & & 4,246 & 29.51 & & 1,334 & 9.29 & & 3,257 & 22.61 & \\
\hline Higher & 2,494 & 67.55 & & 2,173 & 58.87 & & 1.207 & 32.75 & & 1,358 & 36.73 & \\
\hline \multicolumn{13}{|l|}{ Marital Status } \\
\hline Never married & 8,209 & 31.11 & 0.000 & 4,714 & 17.88 & 0.000 & 1,507 & 5.72 & 0.000 & 3,854 & 14.6 & 0.000 \\
\hline Married & 395 & 45.45 & & 292 & 33.56 & & 77 & 8.87 & & 249 & 28.59 & \\
\hline Living with Partner & 347 & 34.94 & & 202 & 20.36 & & 68 & 6.87 & & 96 & 9.67 & \\
\hline Divorced/sep & 162 & 37.76 & & 106 & 24.71 & & 42 & 9.84 & & 97 & 22.61 & \\
\hline Widowed & 120 & 27.78 & & 49 & 11.34 & & 21 & 4.86 & & 35 & 8.10 & \\
\hline \multicolumn{13}{|l|}{ Religion } \\
\hline Traditionalist & 31 & 8.81 & 0.000 & 20 & 5.68 & 0.000 & 5 & 1.42 & 0.000 & 24 & 6.82 & 0.000 \\
\hline Christianity & 8,169 & 41.21 & & 6,047 & 30.52 & & 2,276 & 11.50 & & 5,004 & 25.22 & \\
\hline Islam & 4,505 & 24.27 & & 1,776 & 9.57 & & 473 & 2.55 & & 1,174 & 6.32 & \\
\hline \multicolumn{13}{|l|}{ Employment status } \\
\hline Not working & 12,379 & 33.34 & 0.000 & 7,649 & 20.61 & 0.000 & 2.671 & 7.21 & 0.000 & 6,039 & 16.26 & 0.000 \\
\hline Working & 209 & 19.24 & & 135 & 12.44 & & 47 & 4.33 & & 86 & 7.92 & \\
\hline \multicolumn{13}{|l|}{ Region } \\
\hline North Central & 1,871 & 29.96 & 0.000 & 1,205 & 19.30 & 0.000 & 512 & 8.21 & 0.000 & 1,019 & 16.30 & 0.000 \\
\hline North East & 968 & 14.62 & & 469 & 7.09 & & 165 & 2.50 & & 256 & 3.86 & \\
\hline North West & 2,082 & 21.54 & & 370 & 3.83 & & 151 & 1.56 & & 334 & 3.45 & \\
\hline South East & 1,725 & 38.69 & & 1,042 & 23.38 & & 511 & 11.47 & & 1,168 & 26.18 & \\
\hline South South & 2,375 & 39.22 & & 1,886 & 31.19 & & 737 & 12.22 & & 1,590 & 26.25 & \\
\hline South West & 3,737 & 63.66 & & 2,898 & 49.37 & & 691 & 11.78 & & 1,858 & 31.63 & \\
\hline \multicolumn{13}{|l|}{ Residence } \\
\hline Urban & 7,600 & 48.93 & 0.000 & 5,526 & 35.59 & 0.000 & 2.037 & 13.14 & 0.000 & 3,704 & 23.83 & 0.000 \\
\hline Rural & 5,158 & 22.06 & & 2,344 & 10.03 & & 730 & 3.13 & & 2,521 & 10.77 & \\
\hline \multicolumn{13}{|l|}{ Wealth Index } \\
\hline Lowest & 547 & 8.29 & 0.000 & 41 & 0.62 & 0.000 & 14 & 0.21 & 0.000 & 121 & 1.83 & 0.000 \\
\hline Second & 1,176 & 15.65 & & 212 & 2.83 & & 63 & 0.84 & & 456 & 6.07 & \\
\hline
\end{tabular}


Table 2 Bivariate and Chi-Square analyses of access to mass media messages, and use of family planning (Continued)

\begin{tabular}{|c|c|c|c|c|c|c|c|c|}
\hline Middle & 2,284 & 28.58 & 984 & 12.32 & 307 & 3.85 & 1,166 & 14.57 \\
\hline Fourth & 3,910 & 46.29 & 2,517 & 29.81 & 705 & 8.36 & 1,883 & 22.28 \\
\hline Highest & 4,841 & 57.84 & 4,116 & 49.19 & 1.678 & 20.10 & 2,599 & 31.01 \\
\hline
\end{tabular}

FP Use of family planning

$T V$ Television messages on family planning

Radio Radio messages on family planning

NP Newspaper messages on family planning

Sig Chi Square significance level

planning information on television as against $35.59 \%$ or urban residents. In terms of marital status, $11.34 \%$ of the widowed had access compared to $33.56 \%$ of married respondents. Other socio-demographic groups with relatively higher access to television messages about family planning include people with higher education (58.87 \%), people from South West (49.37\%), and people within the highest wealth quintile $(49.19 \%)$. In terms of access to newspaper information on family planning the following had relatively lower access; the 15-19 years age group (4.47\%), no education group (0.23\%), the widowed (4.86 \%), the working population (4.33\%), North West residents $(1.56 \%)$, rural populations $(3.13 \%)$ and populations within the lowest wealth quintile $(0.21 \%)$.

The use of family planning services also varied across the socio-demographic groups as indicated in Table 2. The use of family planning services increased with an increment in the age of respondents as only $6.82 \%$ of the $15-19$ age-group as against $21.18 \%$ of the $40-44$ agegroup use family planning services. The proportion of users also got reduced to $12.63 \%$ for the $45-49$ agegroup. The other groups that made relatively greater use of family planning services in the country are; people with higher education (36.73\%), the married (28.59\%), people from South West (31.63\%), urban residents $(23.83 \%)$, and people with the highest wealth quintile (31.01\%).

\section{Do access to mass media messages on family planning correlate with use of family planning?}

The Pearson correlation analysis of mass media messages on family planning and utilization of family planning methods generally indicated weak but very significant direct relationships. This means that as access to messages about family planning from the various mass media increases, the use of family planning also increases in the country. Specifically, the greatest correlation for the mass media and use of family planning was found for television messages $(\mathrm{r}=0.239 ; p<0.0001)$ followed by radio messages $(r=0.216 ; p<0.0001)$ while the least correlation was found for access to newspaper messages $(r=0.156 ; p<0.0001)$. These correlation coefficients show that generally, access to family planning messages using these three mass media has been effective in influencing the use of family planning. However, the comprehension of the magnitude of the impacts of these mass media messages, and the spatiodemographics characteristics on use of family planning is necessary in order to have an empirical basis for further designing and implementation of strategies that could enhance their effectiveness in influencing the use of family planning methods in Nigeria. Consequently, the regression analyses were used to highlight the magnitude of the impacts of mass media messages and other spatio-demographic characteristics on the use of family planning methods in Nigeria.

\section{The predictors of use of family planning in Nigeria}

The regression results for the predictors of the use of family planning are shown in Table 3 . In model 1 which depicts the unadjusted regression coefficients, it can be seen that the odds ratio of most of the independent variables increased the likelihood of respondents making use of family planning methods. The only variables that their odds ratio decreased the likelihood of respondents using family planning are the respondents living with a partner $(\mathrm{OR}=0.626 ; p<0.0001)$, the widowed $(\mathrm{OR}=0.516 ; p<$ $0.0001)$, the Islam religion respondents $(\mathrm{OR}=0.922)$, North East residents $(\mathrm{OR}=0.206 ; p<0.0001)$, North West residents $(\mathrm{OR}=0.184 ; p<0.0001)$, respondents who were not working $(\mathrm{OR}=0.443 ; p<0.0001)$, and the rural dwellers $(\mathrm{OR}=0.386 ; p<0.0001)$. Within each of the categories of independent variables (mass media, age group, marital status etc), the following relatively predicted more use of family planning. They are access to television messages $(\mathrm{OR}=3.380 ; p<0.0001), 40-44$ agegroup $(\mathrm{OR}=3.673 ; p<0.0001)$, respondents with postsecondary education $(\mathrm{OR}=19$. 363; $p<0.0001)$, the married $(\mathrm{OR}=2.342 ; p<0.0001)$, the Christian respondents $(\mathrm{OR}=4.610 ; p<0.000)$, the South West residents $(\mathrm{OR}=2.375 ; p<0.0001)$, and the respondents in the highest wealth index $(\mathrm{OR}=24.080 ; p<0.0001)$.

In model 2 in which use of family planning was adjusted for access to mass media messages, the results still showed that access to mass media messages significantly increased the likelihood of respondents making use of family planning with access to television message $(\mathrm{OR}=2.221 ; p<0.0001)$ still predicting 2.221 times more 
of the likelihood of use family planning compared to radio message which was 1.945 times likely to increase use of family planning and newspaper message which was 1.360 times more likely to increase use of family planning. The results also showed that the combined effects of the various mass media messages in the adjusted model reduced their odds ratios relative to their odds ratios in the unadjusted model but still increased the likelihood of respondents making use of family planning. For instance, while the access to radio messages was 3.225 more likely to lead to use of family planning in model 1, it was 1.945 more likely to lead to use of family planning in model 2.

Model 3 shows the combined effects of the independent variables of access to mass media messages and the spatio-demographic characteristics on the dependent variable. The results show that all the variables within each category of the independent variables (mass media, age group, marital status etc) which predicted more likelihood of use of family in the unadjusted model also predicted more likelihood of use of family planning in the adjusted model. The exception to this pattern exists in the mass media category where television messages predicted more likelihood in both the unadjusted model and in the adjusted Model 2 but access to radio massages $(\mathrm{OR}=1.359 ; p<0.0001)$ predicted more likelihood in adjusted model 2. Also in the education category, post-secondary education $(\mathrm{OR}=19.363 ; p<0.0001)$ predicted more likelihood in the unadjusted model but in the adjusted model, secondary education respondents $(\mathrm{OR}=2.709 ; p<0.0001)$ predicted more likelihood of use of family planning. Generally however, model 3 shows that most of the odds ratios of independent variables had lower values compared to the unadjusted values. The variables with increased odds ratios in the adjusted model relative to the unadjusted model are the 30-34 age group $(\mathrm{OR}=3.275 ; p<0.0001)$, the widowed $(\mathrm{OR}=$ $0.604 ; p<0.0001)$, Islam religion respondents $(\mathrm{OR}=$ $0.985)$, the employed respondents $(\mathrm{OR}=0.802)$, and the rural dwellers $(\mathrm{OR}=0.852 ; p<0.001)$.

\section{Discussion}

This study found that access to mass media messages increased the likelihood of respondents making use of family planning. This means that access to information on family planning is effective in positively influencing peoples' attitude towards use of family planning in Nigeria and this results supports earlier findings by other researchers who posited that mass media messages on family planning was effective in increasing the use of family planning $[1,16,25]$. The results of both the bivariate and regression analyses also showed that increase in socioeconomic status leads to a corresponding increase in the use of family planning. These results agree with other findings which showed that people with higher educational qualification are more like to make use of family planning as they are better informed of its importance, and also because they need to use family planning to ensure that their educational pursuits are not truncated by child bearing [36, 41]. Also as the wealth index increases from the lowest category, so also the more the likelihood of their odds ratios predicting use of family planning. In other words, as the wealth of households increase, the household members are more likely to make use of family planning so as to ensure a better quality of life for the household members. This finding is also corroborated by earlier studies which posited that higher socioeconomic status of households leads to higher uptake of family planning [14, 40, 44].

Television messages have the greatest impact on the tendency for people to use family planning, and it is followed in importance by radio messages. The reduction in the explanatory power of the mass media in influencing use of family planning, when spatiodemographic characteristics are added in model 3, shows that the spatio-demographic variables also influence use of family planning by affecting how these mass media messages are received and utilized by respondents. This finding is in agreement with other studies in which they note that other socio-demographic variables such as place of residence, marital status, and employment status play a vital role in determining the use or otherwise of family planning even in the presence of family planning awareness among populations [17-19]. For instance, our findings show that rural respondents are less likely to make use of family planning compared to urban respondents. This also may due to the fact that the urban dwellers have better access to family planning messages (Table 2), and as such has more knowledge about family planning [1].

The results of the regression analyses also revealed significant and positive odds ratios between use of family planning and respondents of all age groups relative to the reference category of the 15-19 age group. This means that increase in age groups significantly increase the likelihood of the use of family planning with the exception of the 45-49 age group. Despite the fact that the odds ratios of this age-group for model $1(\mathrm{OR}=1.976 ; p$ $<0.0001)$, and for model $3(\mathrm{OR}=2.583 ; p<0.0001)$ increases the likelihood of use of family planning, odds ratios were less than the preceding age group. This indicates that even though, this age group still makes use of family planning, their propensity to make use of family planning decreases. This reduction in use of family planning by the $45-49$ age-group is due to the fact that most of them have reached menopause, stopped child bearing, and subsequently, the need for use of family planning becomes minimal [42]. 
Table 3 Regression results of the predictors of current use of family planning

\begin{tabular}{|c|c|c|c|}
\hline Regression variables & Model 1 & Model 2 & Model 3 \\
\hline Intercept & $0.190^{* * *}$ & $0.112^{* * *}$ & $0.012^{* * *}$ \\
\hline Access to radio messages & $3.225^{* * *}$ & $1.945^{* * *}$ & $1.359^{* * *}$ \\
\hline Access to television messages & $3.830^{* * *}$ & $2.221^{* * *}$ & 1.031 \\
\hline Access to newspaper messages & $3.434^{* * *}$ & $1.360^{* * *}$ & 1.120 \\
\hline \multicolumn{4}{|l|}{ Age group } \\
\hline $15-19$ & $\mathrm{RC}$ & & $\mathrm{RC}$ \\
\hline $20-24$ & $2.950^{* * *}$ & & $2.120^{* * *}$ \\
\hline $25-29$ & $2.981^{* * *}$ & & $2.460^{* * *}$ \\
\hline $30-34$ & $3.253^{* * *}$ & & $3.275^{* * *}$ \\
\hline $35-39$ & $3.581^{* * *}$ & & $4.135^{* * *}$ \\
\hline $40-44$ & $3.673^{* * *}$ & & $4.454^{* * *}$ \\
\hline $45-49$ & $1.976^{* * *}$ & & $2.583^{* * *}$ \\
\hline \multicolumn{4}{|l|}{ Education } \\
\hline No education & $\mathrm{RC}$ & & $\mathrm{RC}$ \\
\hline Primary & $6.847^{* * *}$ & & $2.344^{* * *}$ \\
\hline Secondary & $9.741^{* * *}$ & & $2.709^{* * *}$ \\
\hline Higher & $19.363^{* * *}$ & & $2.474^{* * *}$ \\
\hline \multicolumn{4}{|l|}{ Marital Status } \\
\hline Never married & $\mathrm{RC}$ & & $\mathrm{RC}$ \\
\hline Married & $2.342^{* * *}$ & & $1.274^{* *}$ \\
\hline Living with Partner & $0.626^{* * *}$ & & $0.359^{* * *}$ \\
\hline Divorced/sep & $1.709^{* * *}$ & & 0.958 \\
\hline Widowed & $0.516^{* * *}$ & & $0.604^{*}$ \\
\hline \multicolumn{4}{|l|}{ Religion } \\
\hline Traditionalist & $\mathrm{RC}$ & & $\mathrm{RC}$ \\
\hline Christianity & $4.610^{* * *}$ & & $1.579^{*}$ \\
\hline Islam & 0.922 & & 0.985 \\
\hline \multicolumn{4}{|l|}{ Employment status } \\
\hline Not working & $\mathrm{RC}$ & & $\mathrm{RC}$ \\
\hline Working & $0.443^{* * *}$ & & 0.802 \\
\hline \multicolumn{4}{|l|}{ Region } \\
\hline North Central & $\mathrm{RC}$ & & $\mathrm{RC}$ \\
\hline North East & $0.206^{* * *}$ & & $0.387^{* * *}$ \\
\hline North West & $0.184^{* * *}$ & & $0.395^{* * *}$ \\
\hline South East & $1.821^{* * *}$ & & 0.986 \\
\hline South South & $1.827^{* * *}$ & & $0.812^{* *}$ \\
\hline South West & $2.375^{* * *}$ & & $1.294^{* * *}$ \\
\hline \multicolumn{4}{|l|}{ Residence } \\
\hline Urban & $\mathrm{RC}$ & & $\mathrm{RC}$ \\
\hline Rural & $0.386^{* * *}$ & & $0.852^{* *}$ \\
\hline \multicolumn{4}{|l|}{ Wealth Index } \\
\hline Lowest & $\mathrm{RC}$ & & $\mathrm{RC}$ \\
\hline Second & $3.460^{* * *}$ & & $1.530^{* * *}$ \\
\hline
\end{tabular}

Table 3 Regression results of the predictors of current use of family planning (Continued)

\begin{tabular}{lll}
\hline Middle & $9.137^{* * *}$ & $2.276^{* * *}$ \\
Fourth & $15.358^{* * *}$ & $2.797^{* * *}$ \\
Highest & $24.080^{* * *}$ & $3.442^{* * *}$ \\
\hline$R C$ Reference category & & \\
${ }^{*} p<0.05 ;{ }^{* *} p<0.001 ;{ }^{* * * *} p<0.000$ & &
\end{tabular}

The married and the divorced/separated are more likely to make use of family planning relative to the reference category of the never married. Literature show that married respondents are always sexually active and thus are more likely to use family planning to regulate their rate of becoming pregnant especially when their babies are still young [14, 15, 39-43]. With regards to the geo-political zones of the country, the regions that are less likely to make use of family planning are North East, South East and South South while the South West respondents are more likely to make use of family planning, with North Central as the reference category. The reason may be because the Northern part of Nigeria are highly populated have more expanse of land for population expansion unlike the Southern part that has high population densities. Secondly, the religion practices in the Northern parts of Nigeria which encourage polygamy and does noes encourage family planning. This is at variance with what happens in Southern parts of Nigeria where Christianity encourages people to marry one wife. Consequently, the results show that culture (including religion) and place of residence influence use of family planning $[1,14]$. In addition, the results in Table 2 shows that the Northern parts of Nigeria has less access to mass media messages on family planning compared to their Southern counterparts, and as such are less enlightened about the importance of family planning.

\section{Conclusions}

The study showed significant variations within spatiodemographic groups with regards to having access to mass media messages on family planning, and on how they make use of family planning. For instance, Northern Nigeria populations had less access to mass media messages on family planning messages and were also less likely to use family planning, compared to populations in Southern Nigeria. Also, people with lower socio-economic status had less access to mass media and were less likely to use family planning. The correlation results indicated that mass media messages significantly increased use of family planning. Both the bivariate and regression results showed that access to television messages influenced use of family planning more than messages from the other mass media. The regression results also showed that in addition to the influence of mass media in encouraging use of family 
planning, other spatio-demographic variables such as higher educational qualification, increase in age of women, being married, being a from the Southern part of Nigeria, and increase in the wealth of households are the most significant characteristics that encouraged use of family planning in Nigeria. Based on the findings, wider coverage area and improved quality of mass media messages on family planning should be implemented especially in the Northern part of Nigeria. Also, there is the need for improvement in educational attainment of women as it will help to enlighten them on the importance of family planning while at the same time delaying their age of first birth. It will also be necessary to put in place infrastructural facilities such as electricity, and skills acquisition centers that will also create employments especially for the youths, who represent the reproductive cohorts of the population. While employment and skills acquisition will help to ensure that the populace is appropriately engaged in productive economic activities, access to electricity will also help them have access to information about the utility of family planning through various mass media sources. Finally, other communication avenues such as traditional institutions, blogs, and seminars for youths as means of making family planning more acceptable to the population should be explored.

\section{Data availability}

The dataset(s) supporting the conclusions of this article is(are) available in the Demographic and Health Survey repository, in http://dhsprogram.com/data/dataset/Nigeria_ StandardDHS_2013.cfm?flag=1.

\begin{abstract}
Abbreviations
DHS: Demographic and Health Survey; EA: enumeration area; FCT: Federal Capital Territory of Nigeria (Abuja); ICF: Inner City Fund International; LGA: Local Government Area; NPC: National Population commission of Nigeria; NGO: Non-governmental Organization; OR: odds ratio; PSU: primary sampling unit; UKaid: United Kingdom Agency for International Development; USA: United States of America; USAID: United States Agency for International Development.
\end{abstract}

\section{Competing interests}

The authors declare that they have no competing interest.

\section{Authors' contributions}

CKA conceived the study while IDA and CAN drafted the background of the study and helped in proof reading the manuscript. CON and CKA drafted the methodology and carried out data analysis. Finally, CKA compiled and discussed the results of the analysis. All authors read and approved the final manuscript.

\section{Acknowledgment}

The authors are grateful to the DHS program for the permission to use the data, We also thanks all the anonymous participants who are involved in this survey. Finally, the utilization of research facilities of the University of Nigeria, and the Demography and Population Studies Programme of the University of Witwatersrand, South Africa in the preparation of this manuscript are gratefully acknowledged by the authors.

\section{Author details}

'Department of Geography, University of Nigeria Nsukka, Nsukka, Nigeria. ${ }^{2}$ Demography and Population Studies Programme, University of the Witwatersrand, Johannesburg, South Africa. ${ }^{3}$ Department of Mass

Communication, University of Nigeria Nsukka, Nsukka, Nigeria.

Received: 25 August 2015 Accepted: 23 March 2016

Published online: 24 May 2016

\section{References}

1. Omoera OS. Broadcast media in family planning matters in rural Nigeria: the Ebelle scenario. J Commun. 2010;1 (2):77-85.

2. Westoff $C$, Bankole A. Mass media and reproductive behavior in Africa. Demographic and Health Surveys Analytical Reports No. 2. Calverton, Maryland: Macro International Inc; 1997.

3. Dunn JS. Mass media and individual reproductive behavior in Northeast Brazil. Salvador, Brazil: Paper to be presented at the XXIV General Population Conference of the International Union for the Scientific Study of Population; 2001.

4. Kojima $\mathrm{H}$. The effects of mass media on contraception and fertility in African countries. Paper presented for the 1993 seminar on Social, Cultural and Medical Determinants of Contraceptive use, IUSSP XXnd General population Conference, Montreal, Canada.1993

5. Piotrow D, Kincaid L, Hindin M, Lettermaier C, Kuseka I, Silberman T, Zinanga A, Chikara F, Adamchak D, Mbizvo M, Lynn W, Kumah O, Kim Y. Changing men's attitude and behavior: the Zimbabwe male motivation project. Stud Fam Plann. 1992;23(6):365-75.

6. Westoff $C$, Rodriguez $\mathrm{G}$. The mass media and family planning in Kenya. Int Fam Plan Perspect. 1995;21(1):26-31.

7. Bankole $A$, Rodriguez $\mathrm{G}$, Westoff $C$. Mass media messages and reproductive behavior in Nigeria. J Biosoc Sci. 1996;28(2):227-39.

8. Gizaw A, Regassa N. Family planning service utilization in Mojo town, Ethiopia: a population-based study. J Geogr Regional Plannin. 2011;4(6): 355-63.

9. Alemayehu M, Belachew T, Tilahun T. Factors associated with utilization of long acting and permanent contraceptive methods among married women of reproductive age in Mekelle town, Tigray region, north Ethiopia. BMC Pregnancy Childbirth. 2012;16(6):1-9.

10. Kiragu K, Krenn S, Kusemiju B, Ajiboye J, Chidi I, Kalu O. Promoting family planning through mass media in Nigeria: campaigns using public service announcements and a national logo. Baltimore, Maryland: John Hopkins Centre for Communication Programs; 1996.

11. Westoff $C$, Rodriguez $G$. The mass media and family planning in Kenya. DHS Working Paper, Number 4. Columbia, Maryland: Macro International Inc; 1993

12. Bankole A. The role of mass media in family planning promotion in Nigeria. DHS Working Paper, Number 11. Calverton, Maryland: Macro International Inc: 1994.

13. Ekukudo IW. Information as a determinant of utilization of family planning services in rural Akwa lbom state of south-south Nigeria. Mediterr J Soc Sci. 2015;6(4):445-53. doi:10.5901/mjss.2015.v6n4s1p445.

14. Apanga PA, Adam MA. Factors influencing the uptake of family planning services in the Talensi district, Ghana. Pan Afr Med J. 2015;20:10. doi:10.11604/pamj.2015.20.10.5301.

15. Oni GA, McCarthy J. Family planning knowledge, attitudes and practices of males in Ilorin. Niger Int Family Plann Perspect. 1991;17(2):50-4.

16. Isonguyo I, Adindu A. Adolescents and utilization of family planning service in rural community of Nigeria. Res Humanit Soc Sci. 2013;3:1.

17. Jah F, Connolly S, Barker K, Ryerson W. Gender and reproductive outcomes: the effects of a radio serial drama in Northern Nigeria. Int J Popul Res. 2014; 2014:326905. doi:10.1155/2014/326905.

18. Basten S. Mass media and reproductive behavior: serial narratives, soap operas, and telenovelas. The future of Human Reproduction. Working Paper \#7, University of Oxford. 2009.

19. Gupta N, Katende C, Bessinger R. Association of mass media exposure on family planning attitudes and practices in Uganda. Chapel Hill, NC. USA: Measure Evaluation Working Paper, WP-0367, Carolina Population Centre, University of North Carolina; 2003.

20. Van Rossem R, Meekers D. An evaluation of the effectiveness of targeted social marketing to promote adolescent and young adult reproductive health in Cameroon. AIDS Educ Prev. 2000;12(5):383-404. 
21. Jato M, Simbakalia C, Tarasevich M, Awasum D, Kihinga B, Ngirwamungu E. The impact of multimedia family planning promotion on the contraceptive behavior of women in Tanzania. Int Fam Plan Perspect. 1999;25(2):60-7.

22. Rogers E, Vanghan P, Swelehe R, Rao N, Svenkerud P, Sood S. Effects of an entertainment-education radio soap opera on family planning behavior in Tanzania. Stud Fam Plann. 1999;30(3):193-211.

23. Storey D, Boulay M, Karki T, Heckert K, Karmacharya D. Impact of the integrated radio communication project in Nepal, 1994-1997. J Health Commun. 1999:4(4):271-94.

24. Kane T, Gueye M, Speizer I, Pacque-Margolis S, Baran D. The impact of a family planning multimedia campaign in Bamako, Mali. Stud Fam Plann. 1998;29(3):309-23.

25. Valente T, Kim Y, LeHenmaier C, Glass W, Dibba Y. Radio promotion of family planning in the Gambia. Int Fam Plan Perspect. 1994;20(3):96-100

26. Isreal RC, Nagano R. Promoting reproductive health for young adults through social marketing and mass media: a review of trends and practices. Focus on Young Adults Research Series, July 16.1997. Retrieved on 4 July 2015 from http://www.pathfind.org/pf/pubs/focus/RPPS-papers/ social\%20marketing.html

27. Kuhnert B, Nieschlag E. Reproductive function of the ageing male. Hum Reprod Update. 2004;10:327-39.

28. Joffe M, Key J, Best N, Jensen TK, Keiding $\mathrm{N}$. The role of biological fertility in predicting family size. Hum Reprod. 2009;24:1999-2006.

29. de La Rochebrochard E, de Mouzon J, Thépot F, Thonneau P. Fathers over 40 and increased failure to conceive: the lessons of in vitro fertilization in France. Obstet Gynecol Survey. 2006;61:646-7.

30. Sartorius GA, Nieschlag E. Paternal age and reproduction. Hum Reprod Update. 2010;16:65-79.

31. Stover J, McKinnon R, Winfrey B. Spectrum: a model platform for linking maternal and child survival interventions with AIDS, family planning and demographic projections. Int J Epidemiol. 2010;39:17-i10.

32. Goldin C, Katz LF. The power of the pill: oral contraceptives and women's career and marriage decisions. J Political Econ. 2002;110:730-70.

33. Van de Kaa DJ. On the societal impact of modern contraception. In: Beets $G$ Schippers J, te Velde ER, editors. The future of motherhood in Western societies. Late fertility and its consequences. Berlin, Germany: Springer; 2011. p. 49-60.

34. Gerson K. The Unfinished Revolution: How a New Generation is Reshaping Family, Work, and Gender in America. Oxford, UK: Oxford University Press; 2010.

35. Rindfuss RR, Morgan SP, Swicegood G. First births in America. Changes in the Timing of Parenthood. Berkeley, CA: University of California Press; 1988

36. Joshi H. Production, reproduction and education: Women, children and work in a British perspective. Popul Dev Rev. 2002;28:445-74.

37. Goldin C. The quiet revolution that transformed women's employment, education, and family. Am Econ Rev. 2006;96:1-21.

38. Miller AR. The effect of motherhood timing on career path. J Popul Econ. 2011:24:1071-100

39. Eze B, Odeli T. Geographical perspectives of utilization of family planning methods in Enugu urban area of Enugu state, Nigeria. Int I Curr Microbiol Appl Sci. 2014;3(11):464-70.

40. OlaOlorun F, Tsui A. Advancing family planning research in Africa. Afr J Reprod Health. 2010;14(4):9-12.

41. Lee H, Lee T, Shin H, Ahn H, Kim M, Lee M. Patterns and predictors of nonuse of family planning method in Ethiopian women: a panel study. Int Nurs Rev. 2013;60:335-43.

42. Mawajdeh S. Demographic profile and predictors of unmet need for family planning among Jordanian women. J Fam Plann Reprod Health Care. 2007; 33(1):53-6.

43. Nakaie N, Tuon S, Nozaki I, Yamaguchi F, Sasaki Y, Kakimoto K. Family planning practice and predictors of risk of inconsistent condom use among HIV-positive women on anti-retroviral therapy in Cambodia. BMC Public Health. 2014;14:170. doi:10.1186/1471-2458-14-170.

44. Muhindo R, Okonya JN, Groves S, Chenault M. Predictors of contraceptive adherence among women seeking family planning services at reproductive health Uganda, Mityana branch. Int J Popul Res. 2015;2015:574329. Retrieved from http://dx.doi.org/10.1155/2015/574329.

45. Odimegwu CO. Family planning attitudes and use in Nigeria: a factor analysis. Int Fam Plan Perspect. 1999;25(2):86-91.

\section{Submit your next manuscript to BioMed Central and we will help you at every step:}

- We accept pre-submission inquiries

- Our selector tool helps you to find the most relevant journal

- We provide round the clock customer support

- Convenient online submission

- Thorough peer review

- Inclusion in PubMed and all major indexing services

- Maximum visibility for your research

Submit your manuscript at www.biomedcentral.com/submit
Biomed Central 